\title{
A cross-sectional study to evaluate sonographic foetal humerus length for estimation of gestational age in normal singleton pregnancies at a tertiary care centre
}

\author{
Premlata Mital, Richa Ainani, Nupur Hooja*, Priya Sonkhya, Vishwas Pradodh, \\ Kavita Chaudhary, Urmila Kharbas, Saloni Sethi, Jeetendra Singh
}

Department of Obstetrics and Gynecology and Radiodiagnosis, SMS Medical College, Jaipur, Rajasthan, India

Received: 11 June 2019

Accepted: 08 August 2019

*Correspondence:

Dr. Nupur Hooja,

E-mail: drpremlatamital@gmail.com

Copyright: () the author(s), publisher and licensee Medip Academy. This is an open-access article distributed under the terms of the Creative Commons Attribution Non-Commercial License, which permits unrestricted non-commercial use, distribution, and reproduction in any medium, provided the original work is properly cited.

\begin{abstract}
Background: Accurate knowledge of gestational age of the foetus is essential for planning a timely and uneventful outcome. Biparietal diameter, head circumference, abdominal circumference and femur length reliably predict gestational age. The humerus length is not widely used as biometric parameter for determining the GA so the present study was done to estimate foetal gestational age by measuring humerus length between 18 to 36 weeks of normal singleton pregnancies and to compare humerus length with routine parameters.

Methods: This was a hospital based descriptive cross-sectional study, 200 women with viable singleton pregnancy, with known LMP, between 18 weeks to 36 weeks of gestation were included. Various foetal measurements such as biparietal diameter, head circumference, abdominal circumference, femur length and humerus length were measured using electronic calipers on ultrasound. Data were statistically analyzed.

Results: The mean humerus length at 18 weeks was $25.27 \pm 1.16 \mathrm{~mm}$ and at 36 weeks of gestation was $57.11 \pm 1.58$ $\mathrm{mm}$. Simple linear regression analysis shows a strongly significant linear relationship between humerus length and gestational age. Where, gestational age (weeks) $\mathrm{Y}=0.5213 \mathrm{x}$ humerus length $(\mathrm{X})+4.905$; with high degree of correlation coefficient $\left(\mathrm{R}^{2}=0.9785\right.$ and $\left.\mathrm{P} \leq 0.0001\right)$. When Compared with $\mathrm{BPD}, \mathrm{HC}, \mathrm{AC}$ and FL, humerus length also shows a linear correlation.

Conclusions: The measurement of the humerus length can be an important additional parameter for estimating gestational age along with other parameters and can be used to predict the gestational age of fetuses in special circumstances.
\end{abstract}

Keywords: Femur length, Gestational age, Normal pregnancy, Ultrasonography

\section{INTRODUCTION}

Ultrasound (US) has become an indispensible tool in today's obstetric practice. Foetal biometry with the help of US scanning provides the most reliable and important information about the fetal growth and wellbeing. Appropriately performed obstetric ultrasonography has been shown to accurately determine Foetal gestational age. ${ }^{1}$ A good scanning ultrasound machine and an experienced hand are essential for obtaining maximum advantage. ${ }^{2,3}$ It is a safe, non-invasive, convenient, accurate, inexpensive and easily available technique for the antenatal assessment of the foetus., ${ }^{4,5}$ Accurate knowledge of gestational age (GA) of the foetus is vital for timing of appropriate obstetric care; scheduling and interpretation of certain antepartum tests; determining the 
appropriateness of foetal growth; and designing interventions to prevent preterm births, post-term births, and related morbidities. ${ }^{1}$

Traditionally, determining the first day of the LMP is the first step in establishing the EDD. In women with regular cycles and a certain LMP, the EDD is calculated by adding 7 days to the first day of the LMP and adding 9 months (Nagele Rule). ${ }^{6}$ Measurements of the CRL are more accurate the earlier in the first trimester that ultrasonography is performed. ${ }^{7,8}$ The measurement used for dating should be the mean of three discrete CRL measurements when possible and should be obtained in a true midsagittal plane, with the genital tubercle and foetal spine longitudinally in view and the maximum length from cranium to caudal rump measured as a straight line. ${ }^{7,9}$ Mean sac diameter measurements are not recommended for estimating the due date.

Ultrasonography dating in the second trimester typically is based on regression formulas that incorporate variables such as

- The biparietal diameter and head circumference (measured in transverse section of the head at the level of the thalami and cavum septi pellucidi; the cerebellar hemispheres should not be visible in this scanning plane)

- The femur length (measured with full length of the bone perpendicular to the ultrasound beam, excluding the distal femoral epiphysis)

- The abdominal circumference (measured in symmetrical, transverse round section at the skin line, with visualization of the vertebrae and in a plane with visualization of the stomach, umbilical vein, and portal sinus). ${ }^{9}$

Other biometric variables, such as additional long bones and the transverse cerebellar diameter, also can play a role.

Gestational age assessment by ultrasonography in the third trimester (28 0/7 weeks of gestation and beyond) is the least reliable method, with an accuracy of $\pm 21-30$ days. $^{10}$

The above cited parameters reliably predict gestational age and are used routinely and helpful to estimate GA in women who do not remember their last menstrual period (LMP) or where fundal height on abdominal examination does not correspond to the LMP.

Antenatal measurement of foetal parameters and estimated age and weight vary among different populations, depending on their nutritional status, demographic characters and race. It is therefore important that foetal biometry is performed for local population and local charts of normal biometry be constructed. Foetal biometry with the help of ultrasound scanning provides the most reliable and important information about the foetal growth and well being. ${ }^{11,12} \mathrm{FL}$, humerus (HL), tibia and ulna were used in combination to allow of good estimation of GA that may be useful when the BPD measurement may be unreliable, unobtainable or abnormal. Because of its size, visibility, ease of measurement and less mobility than distal limb bones, the femur and humerus are preferred over other long bones as a means of predicting menstrual age. ${ }^{13}$

The foetal humeral length (HL) is not widely used as biometric parameter for determining the GA although it easy to be imaged with US and measured. In cases where the BPD measurement is not reliable femoral length and humeral length allow reliable estimation of foetal age. ${ }^{4}$ Very few studies have been done so far using humerus length to estimate GA so the present study was done to estimate foetal gestational age by measuring humerus length between 18 to 36 weeks of normal singleton pregnancies and to compare humerus length with routine parameters BPD, HC, AC and FL.

\section{METHODS}

This was a hospital based, descriptive cross-sectional study done in the Department of Obstetrics and Gynaecology, S.M.S. Medical College and attached hospitals, Jaipur, Rajasthan from April 2018 to November 2018, 200 women with viable singleton pregnancy between 18 weeks to 36 weeks of gestation and who were willing to be enrolled in the study were included in the study. Women with unknown LMP, irregular menstrual cycle, congenital malformation of foetus, associated medical disorders were excluded from the study. Transabdominal ultrasound was performed in supine position as part of antenatal assessment by using 3.5 $\mathrm{MHz}$ transducer. Various foetal measurements such as $\mathrm{BPD}, \mathrm{HC}, \mathrm{AC}, \mathrm{FL}$ and $\mathrm{HL}$ were measured using electronic calipers.

To locate humerus bone, the transducer was slided upwards transversely towards thorax of the foetus to locate beating heart of the foetus. Then, with a probe rotation of 90 degrees, probe was moved side wards to identify scapula and then the adjoining long bone, the humerus, with probe movements depending upon the position of foetal arm. The ends of the diaphysis of humerus in long axis was imaged. By placing the ultrasound cursers on both ends of the diaphysis, the length was measured in mms.

All data were entered in to MS excel sheet and analyzed. The relationship between gestational age in weeks to foetal humerus length in millimeters was analyzed by simple linear regression. For a given gestational age, predicted values of humerus length was obtained for the $5^{\text {th }}, 10^{\text {th }}, 25^{\text {th }}, 50^{\text {th }}, 75^{\text {th }}, 90^{\text {th }}$ and $95^{\text {th }}$ percentiles to develop a nomogram. Correlation of foetal humerus length with $\mathrm{BPD}, \mathrm{HC}, \mathrm{AC}$ and femur length was also determined by using linear regression analysis. $\mathrm{P}$ value of less than 0.05 was considered as significant. 


\section{RESULTS}

Table 1 shows ultrasonographic measurement of foetal humerus length in $\mathrm{mm}($ mean $\pm \mathrm{SD})$ for a given gestational age between 18 to 36 weeks. The minimum humerus length was $22 \mathrm{~mm}$ at 18 weeks and maximum was $60.2 \mathrm{~mm}$ at 36 weeks. The mean sonographic humerus length at 18 weeks is $25.27 \pm 1.16 \mathrm{~mm}$ and at 36 weeks of gestation is $57.11 \pm 1.58 \mathrm{~mm}$. There was two-fold increase in humerus length from 18 weeks to 36 weeks. It demonstrates a linear relationship between foetal humerus length and gestational age.

The mean femur length at 18 and 36 weeks was $28.81 \pm 1.06 \mathrm{~mm}$ and $68.11 \pm 1.37 \mathrm{~mm}$ respectively and mean humerus length at 18 and 36 weeks was $25.27 \pm 1.16$ $\mathrm{mm}$ and $57.11 \pm 1.58 \mathrm{~mm}$ respectively. It was observed that the femur length gradually increased from $27 \mathrm{~mm}$ to $69.7 \mathrm{~mm}$ and humerus length increased from $22 \mathrm{~mm}$ to $60.2 \mathrm{~mm}$ along with the increasing foetal GA from 18 to 36 weeks. The mean BPD at 18 weeks and 36 weeks was $40.99 \pm 3.12 \mathrm{~mm}$ and $85.83 \pm 1.47 \mathrm{~mm}$ respectively. The mean $\mathrm{HC}$ at 18 weeks and 36 weeks was $148.96 \pm 7.59$ $\mathrm{mm}$ and $317.2 \pm 9.50 \mathrm{~mm}$ respectively. The mean $\mathrm{AC}$ at 18 weeks and 36 weeks was $120.97 \pm 1.16 \mathrm{~mm}$ and $302.26 \pm 8.25 \mathrm{~mm}$ respectively (Table 2 ). When plotted on a graph all parameters showed a linear relationship with gestational age (Figure 1).
Table 1: Foetal humerus length ( $\mathrm{mm})$ according to gestational age (weeks).

\begin{tabular}{|llll|}
\hline $\begin{array}{l}\text { GA } \\
(\text { weeks })\end{array}$ & $\begin{array}{l}\text { No. of } \\
\text { cases }\end{array}$ & $\begin{array}{l}\text { Lower limit } \\
\text { Upper limit }(\mathrm{mm})\end{array}$ & $\begin{array}{l}\text { Mean HL } \\
(\mathrm{mm}) \pm \text { SD }\end{array}$ \\
\hline 18 & 15 & $22.0-27.0$ & $25.27 \pm 1.16$ \\
\hline 19 & 22 & $22.0-29.0$ & $26.23 \pm 1.60$ \\
\hline 20 & 35 & $26.5-31.0$ & $29.01 \pm 1.48$ \\
\hline 21 & 21 & $27.0-32.8$ & $31.04 \pm 1.25$ \\
\hline 22 & 13 & $31.0-34.8$ & $32.91 \pm 1.09$ \\
\hline 23 & 9 & $32.0-37.5$ & $34.78 \pm 2.12$ \\
\hline 24 & 13 & $35.5-39.5$ & $37.13 \pm 1.15$ \\
\hline 25 & 8 & $37.9-41.6$ & $39.63 \pm 1.26$ \\
\hline 26 & 6 & $39.9-42.9$ & $41.64 \pm 1.22$ \\
\hline 27 & 3 & $42.8-44.6$ & $43.63 \pm 0.90$ \\
\hline 28 & 4 & $42.6-46.5$ & $45.07 \pm 1.77$ \\
\hline 29 & 5 & $47.9-50.3$ & $49.22 \pm 0.91$ \\
\hline 30 & 4 & $49.8-51.2$ & $50.2 \pm 0.67$ \\
\hline 31 & 6 & $49.9-51.3$ & $50.56 \pm 0.52$ \\
\hline 32 & 6 & $51.2-52.5$ & $51.91 \pm 1.44$ \\
\hline 33 & 7 & $52.2-54.2$ & $53.02 \pm 0.66$ \\
\hline 34 & 6 & $53.2-55.9$ & $54.81 \pm 1.14$ \\
\hline 35 & 12 & $53.7-58.2$ & $56.16 \pm 1.34$ \\
\hline 36 & 6 & $55.9-60.2$ & $57.11 \pm 1.58$ \\
\hline
\end{tabular}

Table 2: Mean value of foetal HL, BPD, HC, AC and FL from 18 to 36 weeks of gestation.

\begin{tabular}{|lllllll|}
\hline GA & No. of cases & Mean HL & Mean BPD & Mean HC & Mean AC & Mean FL \\
\hline 18 & 15 & $25.27 \pm 1.16$ & $40.99 \pm 3.12$ & $148.96 \pm 7.59$ & $120.97 \pm 1.16$ & $28.81 \pm 1.06$ \\
\hline 19 & 22 & $26.23 \pm 1.60$ & $44.48 \pm 4.52$ & $162.54 \pm 6.86$ & $140.73 \pm 4.01$ & $30.45 \pm 2.53$ \\
\hline 20 & 35 & $29.01 \pm 1.48$ & $47.74 \pm 4.68$ & $176.86 \pm 8.56$ & $145.74 \pm 4.06$ & $33.49 \pm 1.97$ \\
\hline 21 & 21 & $31.04 \pm 1.25$ & $50.82 \pm 5.06$ & $192.8 \pm 6.16$ & $153.38 \pm 3.95$ & $34.40 \pm 1.88$ \\
\hline 22 & 13 & $32.91 \pm 1.09$ & $52.43 \pm 4.23$ & $202.01 \pm 7.47$ & $155.2 \pm 8.02$ & $37.08 \pm 1.10$ \\
\hline 23 & 9 & $34.78 \pm 2.12$ & $53.78 \pm 2.28$ & $206.3 \pm 6.77$ & $165.68 \pm 1.86$ & $39.6 \pm 1.89$ \\
\hline 24 & 13 & $37.13 \pm 1.15$ & $56.38 \pm 4.18$ & $217.11 \pm 3.51$ & $185.38 \pm 3.51$ & $42.30 \pm 1.16$ \\
\hline 25 & 8 & $39.63 \pm 1.26$ & $61.78 \pm 2.10$ & $229.9 \pm 5.96$ & $194.32 \pm 7.68$ & $44.83 \pm 2.17$ \\
\hline 26 & 5 & $41.64 \pm 1.22$ & $64.68 \pm 0.70$ & $239.9 \pm 3.61$ & $204.62 \pm 7.26$ & $46.74 \pm 1.10$ \\
\hline 27 & 3 & $43.63 \pm 0.90$ & $66.23 \pm 1.85$ & $244.73 \pm 4.11$ & $216.56 \pm 5.62$ & $48.03 \pm 1.15$ \\
\hline 28 & 4 & $45.07 \pm 1.77$ & $70.4 \pm 1.64$ & $259.45 \pm 5.44$ & $221.45 \pm 9.63$ & $51.25 \pm 0.75$ \\
\hline 29 & 5 & $49.22 \pm 0.91$ & $73.18 \pm 3.28$ & $266.9 \pm 9.53$ & $232.36 \pm 5.36$ & $54.74 \pm 1.99$ \\
\hline 30 & 4 & $50.2 \pm 0.67$ & $74.42 \pm 2.66$ & $271.97 \pm 7.43$ & $243.25 \pm 3.60$ & $55.7 \pm 1.71$ \\
\hline 31 & 6 & $50.56 \pm 0.52$ & $78.5 \pm 2.62$ & $280.46 \pm 6.17$ & $253.03 \pm 5.71$ & $56.7 \pm 1.78$ \\
\hline 32 & 6 & $51.91 \pm 1.44$ & $80.76 \pm 0.66$ & $290.88 \pm 1.80$ & $265.91 \pm 6.59$ & $59.93 \pm 1.44$ \\
\hline 33 & 7 & $53.02 \pm 0.66$ & $81.75 \pm 3.34$ & $297.35 \pm 9.60$ & $270.05 \pm 6.05$ & $62.82 \pm 0.97$ \\
\hline 34 & 6 & $54.81 \pm 1.14$ & $83.12 \pm 1.27$ & $301.3 \pm 5.06$ & $273.68 \pm 6.98$ & $64.98 \pm 0.78$ \\
\hline 35 & 12 & $56.16 \pm 1.34$ & $84.22 \pm 2.11$ & $302.47 \pm 5.87$ & $282.24 \pm 6.71$ & $66.76 \pm 1.50$ \\
\hline 36 & 6 & $57.11 \pm 1.58$ & $85.83 \pm 1.47$ & $317.2 \pm 9.50$ & $302.26 \pm 8.25$ & $68.11 \pm 1.37$ \\
\hline & & & & & & \\
\hline
\end{tabular}

In Table 3, we have developed a nomogram for foetal humerus length in millimeters for women attending ANC. Table 4 summarizes relationship of foetal humerus length with gestational age, BPD, HC, AC and femur length. The foetal humerus length showed a significant linear correlation with GA, BPD, HC, AC and FL $(\mathrm{P}<0.0001)$. 
The correlation was the highest with FL, with the adjusted $\mathrm{R}^{2}$ being 0.9816 , followed by GA $(0.9785)$, AC (0.9646), HC (0.9603), and was the least with BPD (0.9266). Simple linear regression analysis shows a strongly significant positive linear relationship between humerus length and gestational age. (Figure 2) Where, gestational age (weeks) $\mathrm{Y}=0.5213 \mathrm{x}$ humerus length $(\mathrm{X})$
+4.905 ; with high degree of correlation coefficient $\left(\mathrm{R}^{2}\right.$ $=0.9785$ and $\mathrm{P} \leq 0.0001)$. Simple linear regression analysis shows a strongly significant positive linear relationship between femur length and gestational age. (Figure 3) Where, gestational age (weeks) $\mathrm{Y}=0.4361 \mathrm{x}$ femur length $(\mathrm{X})+5.684$; with high degree of correlation coefficient $\left(\mathrm{R}^{2}=0.9815\right.$ and $\left.\mathrm{P} \leq 0.0001\right)$.

Table 3: Nomogram of foetal humerus length $(\mathrm{mm})$ according to percentile distribution.

\begin{tabular}{|c|c|c|c|c|c|c|c|c|}
\hline GA (weeks) & No. of foetuses & $5^{\text {th }}$ & $10^{\text {th }}$ & $25^{\text {th }}$ & $50^{\text {th }}$ & $75^{\text {th }}$ & $90^{\text {th }}$ & $95^{\text {th }}$ \\
\hline 18 & 15 & 22 & 24 & 25 & 25 & 26 & 27 & 27 \\
\hline 19 & 22 & 24 & 24 & 26 & 26 & 27 & 28 & 28 \\
\hline 20 & 35 & 26.5 & 26.8 & 28 & 29 & 30 & 31 & 31 \\
\hline 21 & 21 & 29.9 & 29.9 & 30.8 & 31 & 31.8 & 32.2 & 32.8 \\
\hline 22 & 13 & 31 & 31.8 & 32.1 & 32.9 & 33.8 & 34 & 34.8 \\
\hline 23 & 9 & 32 & 32 & 33.5 & 34.9 & 36.6 & 37.5 & 37.5 \\
\hline 24 & 13 & 35.5 & 35.8 & 36.2 & 37 & 37.8 & 38.6 & 39.5 \\
\hline 25 & 8 & 37.9 & 37.9 & 38.7 & 39.5 & 40.5 & 41.6 & 41.6 \\
\hline 26 & 6 & 39.9 & 39.9 & 41 & 41.8 & 42.6 & 42.9 & 42.9 \\
\hline 27 & 3 & 42.8 & 42.8 & 42.8 & 43.5 & 44.6 & 44.6 & 44.6 \\
\hline 28 & 4 & 42.6 & 42.6 & 43.8 & 45.6 & 46.3 & 46.5 & 46.5 \\
\hline 29 & 5 & 47.9 & 47.9 & 48.9 & 49.2 & 49.8 & 50.3 & 50.3 \\
\hline 30 & 4 & 49.8 & 49.8 & 49.8 & 49.9 & 50.6 & 51.2 & 51.2 \\
\hline 31 & 6 & 49.9 & 49.9 & 50.2 & 50.5 & 50.9 & 51.3 & 51.3 \\
\hline 32 & 6 & 51.2 & 51.2 & 51.8 & 51.9 & 52.1 & 52.5 & 52.5 \\
\hline 33 & 7 & 52.2 & 52.2 & 52.6 & 52.8 & 53.5 & 54.2 & 54.2 \\
\hline 34 & 6 & 53.2 & 53.2 & 54.1 & 54.8 & 55.9 & 56 & 56 \\
\hline 35 & 12 & 53.7 & 53.9 & 55.6 & 56.2 & 57.1 & 57.5 & 58.2 \\
\hline 36 & 6 & 55.9 & 55.9 & 56.2 & 56.5 & 57.2 & 60.2 & 60.2 \\
\hline
\end{tabular}

Table 4: Summary of relationship of humerus length with GA, BPD, HC, AC and FL.

\begin{tabular}{|c|c|c|c|c|}
\hline $\mathrm{X}$ axis & Y axis & Regression formula & Correlation coefficient & P value \\
\hline \multirow{5}{*}{ Humerus length } & GA & $Y=0.5213 \times X+4.905$ & 0.9785 & $<0.0001$ \\
\hline & BPD & $Y=1.357 x X+8.114$ & 0.9266 & $<0.0001$ \\
\hline & $\mathrm{HC}$ & $Y=4.769 x X+39.25$ & 0.9603 & $<0.0001$ \\
\hline & $\mathrm{AC}$ & $Y=5.700 \times X+53.89$ & 0.9646 & $<0.0001$ \\
\hline & FL & $Y=0.8276 x X+1.880$ & 0.9816 & $<0.0001$ \\
\hline
\end{tabular}

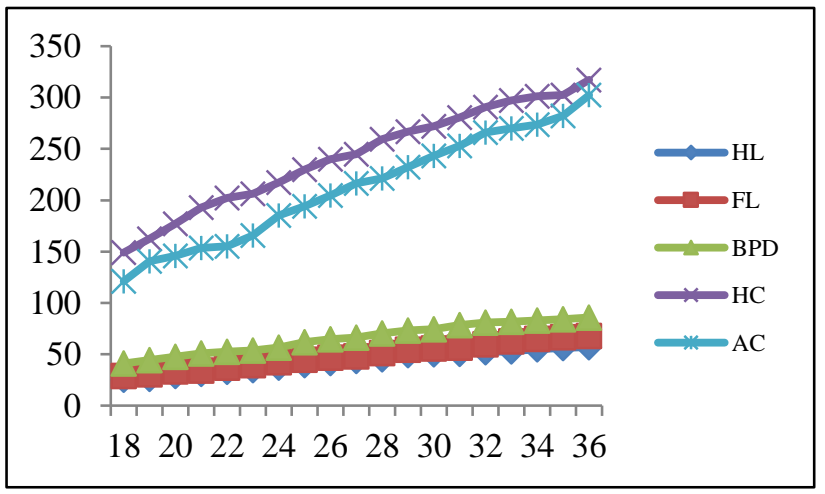

Figure 1: The mean values of HL, BPD, HC, FL and AC from 18 to 36 weeks of gestation.

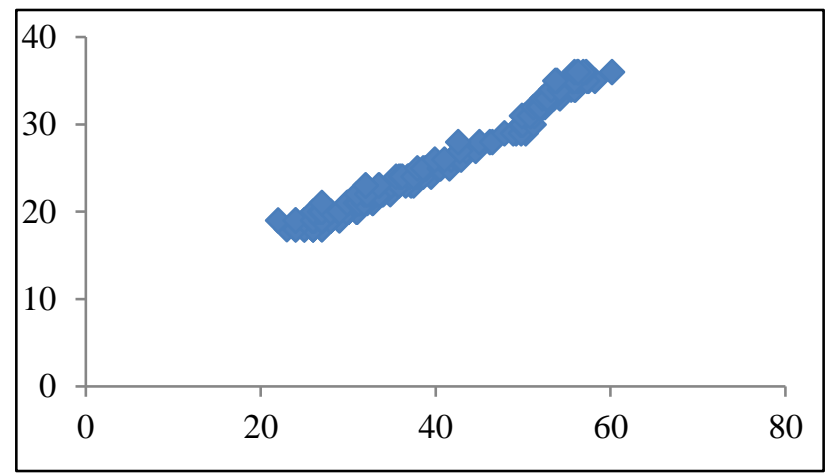

Figure 2: Relationship between foetal length of humerus in $\mathrm{mm}(\mathrm{X}$ axis) and gestational age in weeks (Y axis). 
Gestational age wise, both femur and humerus lengths were compared. The association between HL and FL for GA was also positively correlated and are strongly significant $(\mathrm{p}<0.0001)$. These are supported by the scatter graph plotted between FL and HL according to gestational age from 18 to 36 weeks, which shows a good correlation between the two variables (Figure 4).

When compared with BPD, HC and AC, humerus length also showed a linear correlation (Figure 5, 6, 7).

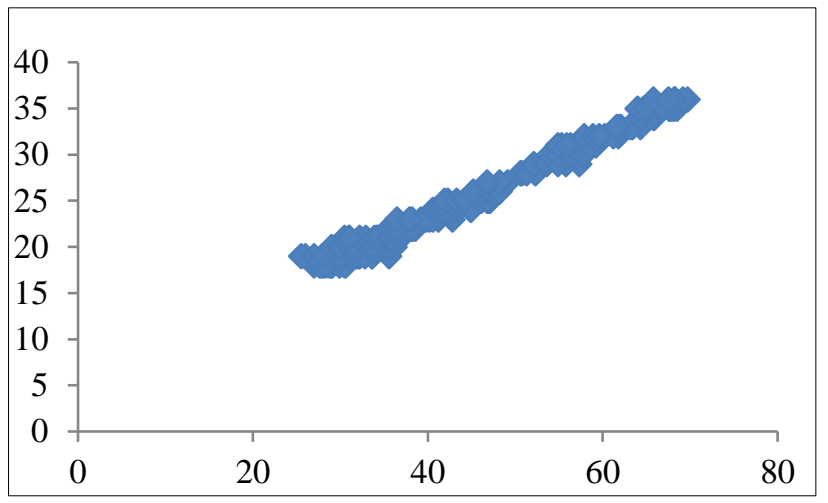

Figure 3: Relationship between foetal femur length in $\mathrm{mm}(\mathrm{X}$ axis) and gestational age in weeks ( $\mathrm{Y}$ axis).

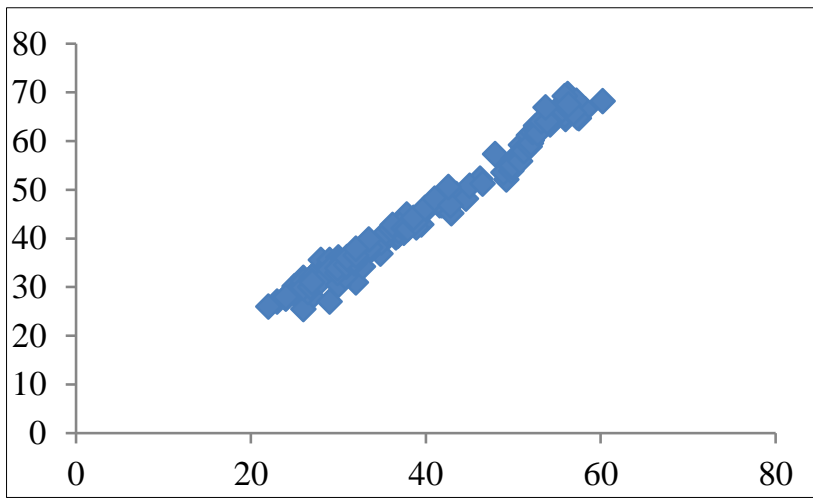

Figure 4: Relationship between foetal humerus length (X axis) and femur length ( $Y$ axis).

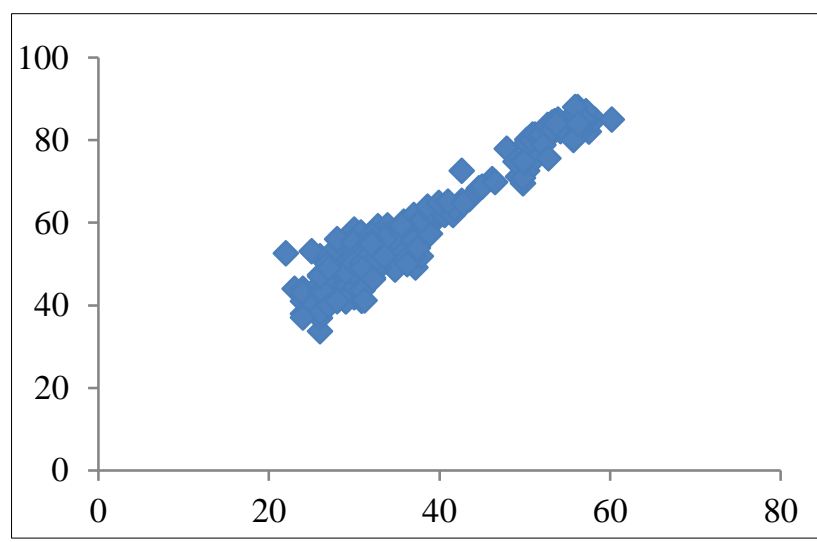

Figure 5: Relationship between foetal humerus length ( $\mathrm{X}$ axis) and BPD (Y axis).

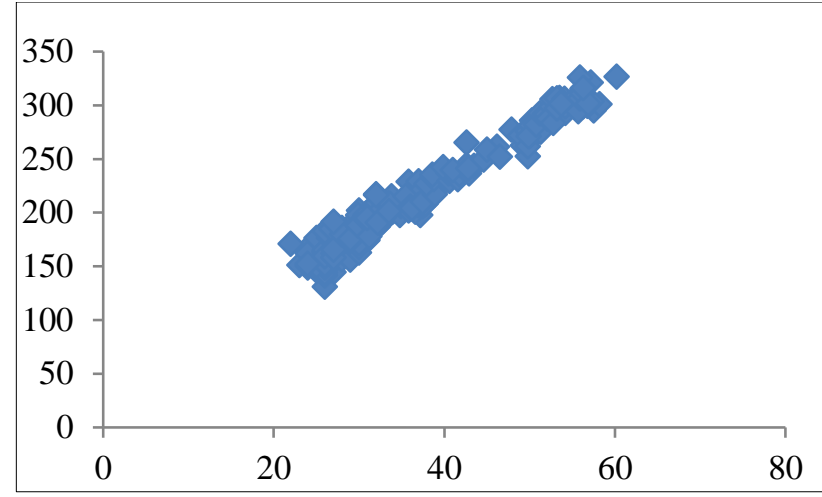

Figure 6: Relationship between foetal humerus length ( $\mathrm{X}$ axis) and HC (Y axis).

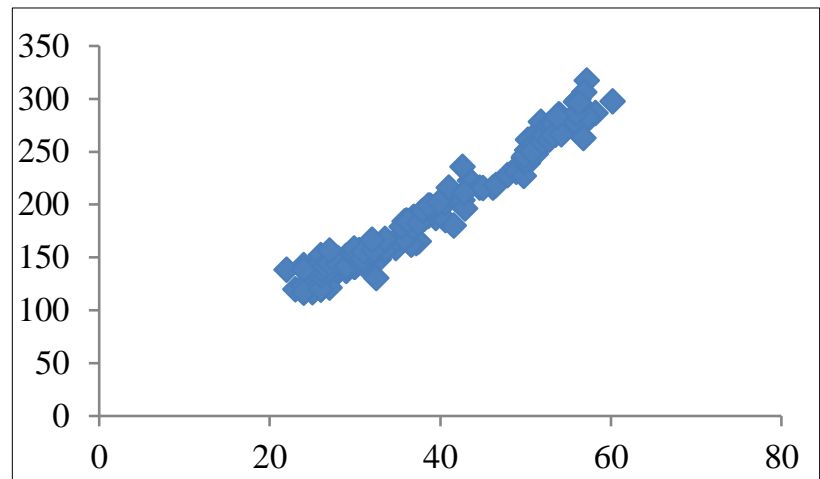

Figure 7: Relationship between foetal humerus length ( $\mathrm{X}$ axis) and $\mathrm{AC}$ (Y axis).

\section{DISCUSSION}

This study was done on 200 women with normal singleton gestations having regular menstrual cycles and known LMP to find accuracy of ultrasound in estimation of gestational age by humeral length and to compare it with other parameters used routinely. The femur length is already an established ultrasound parameter for estimation of foetal gestational age. Foetal humerus length is not currently used parameter for assessment of gestational age. There are very few studies on estimation of gestational age by humerus length because humerus is difficult to define accurately, because of its proximity to the chest wall and its apparent continuity with the scapula and clavicle.

In the study mean humerus length at 18 weeks was $25.27 \pm 1.16 \mathrm{~mm}$ and at 28 weeks it was $45.07 \pm 1.77 \mathrm{~mm}$. The mean femur length at 18 and 28 weeks was $28.81 \pm 1.06 \mathrm{~mm}$ and $51.25 \pm 0.75 \mathrm{~mm}$ respectively. The mean length of humerus and femur in the study was lower than that observed by Tahmasebpour AR et al 2012 in their study. ${ }^{14}$ They observed that mean humerus length at 18 weeks was $26.3 \pm 15.5 \mathrm{~mm}$ and at 28 weeks it was $47.9 \pm 10.2 \mathrm{~mm}$. The mean femur length at 18 and 28 weeks was $26.9 \pm 15.6 \mathrm{~mm}$ and $52.4 \pm 21.8 \mathrm{~mm}$ respectively. There was strong positive correlation between HL and GA in the study; this correlation is not 
so different from the correlation observed between FL and GA (0.9785 vs.0.9815). These results reflect the validity of HL and FL in determining the gestational age. Our results were in accordance with studies done in the past. In a study done by Moawia Gameraddin et al, which was a descriptive cross-sectional study conducted in Dream Specialized hospital in Khartoum State from the period of August to October 2015. The study concluded that both FL and HL were similar and reliable to estimate the GA. There was strong positive correlation between HL and GA. The HL is a basic foetal bone biometry in determination of the gestational age and could be used in accompany with FL to detect foetal bone abnormalities. ${ }^{15}$

In another study carried out by Vivek Patre et al correlation coefficient calculated for HL and GA (0.9704) was found it to be a reliable parameter. A statistically significant curvilinear correlation was observed between $\mathrm{HL}$ and GA indicating it to be a reliable indicator of foetal GA. HL would contribute to maximum accuracy next to FL among all the other parameters. ${ }^{4}$

Nagesh $\mathrm{R}$ et al in their study observed the association of GA with FL and HL by Pearson coefficient correlation and stated that they are positively correlated and are significant. They concluded that humerus length is a reliable parameter for estimation of foetal gestational age and there is no much difference between FL and HL in establishing foetal gestational age. ${ }^{5}$

Tahmasebpour AR et al in their study observed a linear relationship between menstrual age and both femur diaphysis length $\left(\mathrm{R}^{2}=0.957\right)$ and humerus diaphysis length $\left(\mathrm{R}^{2}=0.941\right)$. They also concluded that shortening of foetal long bones such as humerus and femur is a sonographic soft marker for screening Down syndrome in the second trimester. ${ }^{14}$

For each patient, several biometric parameters were obtained including BPD, HC, AC, FL, and HL at different gestation from 18 to 36 weeks. The coefficient of correlation of BPD $(r=0.9626), \mathrm{FL}(\mathrm{r}=0.9907), \mathrm{HC}$ $(\mathrm{r}=0.9799), \mathrm{AC}(\mathrm{r}=0.9821)$, and $\mathrm{HL}(\mathrm{r}=0.9891)$ observed in present study showed a high degree of linear relationship with GA. The results were consistent with that observed by V Patre et al. ${ }^{4}$

\section{CONCLUSION}

Ultrasound is a non-invasive, sensitive, simple and cost effective tool to assess foetal bone biometrics. Sonographic measurement of diaphyseal lengths of humerus and femur is reliable to estimate GA. A strong positive correlation between HL and GA was observed in present study. The measurement of the humerus length can be an important additional parameter for estimating gestational age along with other parameters and can be used in certain conditions like hydrocephalous, anencephaly where abnormality of BPD and $\mathrm{HC}$ is suspected or in skeletal dysplasia and dwarfism where abnormality of femur length is suspected.

Funding: No funding sources

Conflict of interest: None declared

Ethical approval: The study was approved by the Institutional Ethics Committee

\section{REFERENCES}

1. Reddy UM, Abuhamad AZ, Levine D, Saade GR. Fetal imaging: executive summary of a joint Eunice Kennedy Shriver National Institute of Child Health and Human Development, Society for Maternal-Fetal Medicine, American Institute of Ultrasound in Medicine, American College of Obstetricians and Gynecologists, American College of Radiology, Society for Pediatric Radiology, and Society of Radiologists in Ultrasound Fetal Imaging workshop. Fetal imaging workshop invited participants. Obstet Gynecol. 2014;123:1070-82.

2. Rowitz L. Health management information systems: methods and practical. N Engl J Med.2001;21:225344.

3. Rihab MA, Bushra HA, Salah MA, Mohamed TI. The accuracy of gestational age predicted from femur and humerus length in Saanen goats using ultrasonography. Acta Vet Brno. 2012;81:295-9.

4. Patre V, Aryan AK, Sahu P, Patre V. Ultrasonographic evaluation of fetal humerus length for assessment of gestational age and its comparison with other conventional parameters. Int J Sci Stud. 2015;3(7):58-64.

5. Nagesh R, Pramila SVV, Shukla AK. Ultrasonographic estimation of foetal gestational age by humerus length and its comparison with femur length. J. Evid. Based Med. Healthc. 2016;3(74);4040-4.

6. Gaharwar A, Tiwari V. Correlation between Crown Rump Length of Fetus and Gestational Age in First Trimester of Pregnancy in North Indian Population. Int J Med Res Prof. 2019 May;5(3):102-4.

7. Robinson HP, Fleming JE. A critical evaluation of sonar "crown-rump length" measurements. Br J Obstet Gynaecol. 1975;82:702-10.

8. Pexsters A, Daemen A, Bottomley C, Schoubroeck VD, Catte L, Moor B, et al. New crown-rump length curve based on over 3500 pregnancies. Ultrasound Obstet Gynecol. 2010;35:650-5.

9. Verburg BO, Steegers EA, Ridder M, Snijders RJ, Smith E, Hofman A. New charts for ultrasound dating of pregnancy and assessment of fetal growth: longitudinal data from a population-based cohort study. Ultrasound Obstet Gynecol. 2008;31:388-96.

10. Methods for estimating the due date. Committee Opinion No. 700. American College of Obstetricians and Gynecologists. Obstet Gynecol. 2017;129:e1504.

11. Shehzad K, Ali M, Zaid S. Fetal Biometry. Pak J Med Sci. 2006;22(4):503-8. 
12. Rao CBR, Sreepadma S. The study of the humerus and femur length as combined predictors of the gestational age of human fetuses using ultrasonography. Int J Res Med Sci. 2017;5:2701-5.

13. Rao CBR, Sreepadma S, Kalghatgi RN. The study of relation between the gestational age of human fetuses and the diaphyseal length of femur using ultrasonography. Int J Anat Res. 2017;5(1):3342-9.

14. Tahmasebpour AR, Pirjani R, Rahimi-Foroushani A, et al Normal ranges for fetal femur and humerus diaphysis length during the second trimester in an Iranian population. J Ultrasound Medicine. 2012;31(7):991-5.

15. Gameraddin M, Abdelmaboud S, Alshoabi S. The role of fetal humeral length in determination of gestational age compared with femoral length using ultrasonography. IOSR-JDMS. 2015;14(5):65-8.

Cite this article as: Mital P, Ainani R, Hooja N, Sonkhya P, Pradodh V, Chaudhary K, et al. A crosssectional study to evaluate sonographic foetal humerus length for estimation of gestational age in normal singleton pregnancies at a tertiary care centre. Int J Reprod Contracept Obstet Gynecol 2019;8:3622-8. 